\title{
Role of Autologous Fibrin Glue (AFG) to Reduce Drainage Volume After Modified Radical Mastectomy for Breast Cancer
}

\author{
Yohana Azhar ${ }^{1 *}$, Ahmad Iffa Maududy ${ }^{1}$, Nadjwa Zamalek Dalimoenthe ${ }^{2}$ \\ ${ }^{1}$ Division Oncology, Head and Neck Surgery Department of Surgery Hasan Sadikin General Hospital/Faculty of Medicine, \\ Universitas Padjadjaran, Bandung, Indonesia. \\ ${ }^{2}$ Department of Clinical Pathology, Hasan Sadikin General Hospital/Faculty of Medicine Universitas Padjadjaran, Bandung, \\ Indonesia.
}

\section{ARTICLE INFO}

Received : 11 January 2021

Reviewed : 23 February 2021

Accepted : 21 May 2021

\section{Keywords:}

autologous fibrin glue, breast cancer, mastectomy, seroma

\begin{abstract}
A B STRACT
Background: Seroma is arguably the most significant complication that can happen after mastectomy. Although seroma is not a life-threatening complication, this condition can lead to severe morbidities. This situation can cause prolonged hospital stays and delayed adjuvant therapy. In this regard, autologous fibrin glue is a hemostatic agent that can accelerate fibrin formation, stop vascular oozing, and decrease dead space. Therefore, this research was performed to evaluate autologous fibrin glue function in lowering seroma volume after mastectomy and shortening the length of hospital stay.
\end{abstract}

\begin{abstract}
Methods: This randomized control trial research was designed to compare the effect of autologous fibrin glue to a control group that did not receive autologous fibrin glue. Seroma volume was calculated every 24 hours. The drains were then removed after the production of seroma less than $30 \mathrm{~mL} / 24$ hours.
\end{abstract}

\author{
*Corresponding author: \\ Yohana Azhar \\ Division Oncology, Head and Neck \\ Surgery Department of Surgery Hasan \\ Sadikin General Hospital/Faculty of \\ Medicine, Universitas Padjadjaran, \\ Bandung, Indonesia \\ yohana_kevinzo@yahoo.com
}

Results: We recruited 20 patients for each of the two groups who met the inclusion criteria. Age, histopathology type, breast cancer stage, number of lymph nodes, and tumor size did not significantly differ. However, patients in the fibrin glue group had significantly lower cumulative drain production. The median seroma volume in the treatment group was $9.30 \mathrm{~mL}$, while the median in the control group was $20.90 \mathrm{~mL}(p<0.05)$.

Conclusions: Autologous fibrin glue significantly decreased seroma formation and length of hospital stay.

\section{INTRODUCTION}

Breast cancer is the second leading cause of death in Indonesia, with an incidence of about 65,858 new cases and causing more than 22,430 deaths each year. In Hasan Sadikin General Hospital Bandung, West Java, Indonesia, there were 913 new cases reported from January 2014 until December 2018 [1,2].

Operative management for breast cancer is divided into breast-conserving therapy and mastectomy with or without axillary lymph node dissection, depending on the disease stage. At Hasan Sadikin General Hospital, $75.1 \%$ of breast cancers underwent a mastectomy, so seroma is still the biggest problem. Seroma formation is the most common postoperative complication after mastectomy, with an incidence of up to 30\% [3]. According to unpublished data conducted by Junior in 2010 at the Department of Oncology, Head and Neck Surgery Hasan Sadikin General Hospital Bandung, the incidence of seroma after mastectomy was $62.5 \%$ [4]. Although seroma is not a life-threatening complication, it can lead to many problems, such as skin flap necrosis, pain, infection, delayed wound healing, surgical wound reopening, predisposition to sepsis, and lymphedema. In addition, the excessive fluid collection will stretch the skin so that it becomes saggy and causes discomfort 
to the patient. These things can interfere healing process, lengthen the duration of hospital stays, and cause a delay in further therapy [5].

In this regard, fibrin glue has been used in surgical procedures for more than 30 years. One of the advantages of fibrin glue as a hemostatic and tissue adhesion agent has evolved in various surgical procedures, including cardiac, eye, vascular, liver, prostate, thoracic, cosmetic, orthopedic, and gynecological surgery [6].

Fibrin glue, light-activated fibrin sealant, and transdermal photopolymerized adhesive have been associated with reduced fluid build-up post-mastectomy through various studies. Fibrin glue acts by lessening the number of disrupted lymphatics and minutes vessels during axillary dissection resulting in lowering seroma output and providing hemostasis by controlling the hematomas, which may delay wound healing. Furthermore, the fibrin glue has been recommended to interfere with broken tissues during surgery, promoting the emergence of fibroblasts, thereby enhancing wound closure through blockage of dead spaces by tissue adhesion. However, commercial concentrates are expensive and inconvenient [7].

For this reason, autologous fibrin glue (AFG) is taken from the patient's blood and is highly safe from infectious diseases, and prevents allergic reactions caused by bovine thrombin in commercial fibrin glue [8]. However, conflicting results have been reported regarding AFG used in a mastectomy. Therefore, this study aimed to examine whether AFG can reduce seroma production and shorten hospital length of stay since AFG is inexpensive and safe $[7,8]$.

\section{METHODS}

This randomized controlled trial research was conducted at the Department of Oncology, Head and Neck Surgery from January 2020 to July 2020. The study was reviewed by the ethics committee of Hasan Sadikin General Hospital No. LB.02.01/X.6.5/3/2020. The study adhered to CONSORT guidelines. (We have not registered this study to clinical trial registration, but we will do it later).

\section{Patients}

In the current work, forty consecutive patients diagnosed with breast cancer and treated by MRM were recruited. The patients who received rated preoperative chemotherapy and radiotherapy were excluded. The patients with previous axillary surgery and patients with comorbidity such as diabetes mellitus, hypertension, and cardiovascular disease were also excluded. Patients were then randomized into two groups: the experimental group and the control group. Patients were randomly divided by closed-envelop into two groups.

\section{Autologous fibrin glue preparation}

The AFG was prepared at the Department of Clinical Pathology of Hasan Sadikin General Hospital Bandung. All recruited patients eligible for AFG were obtained for their blood. Blood processing was performed with a standard laboratory centrifuge (Rotanta 460, Andreas Hettich GmbH Co KG; Tuttlingen, Germany) equipped with a specially designed rotor for automated production of autologous blood derivatives. All photometric measurements were performed with a microplate photometer (Multiclan FC, Thermo Fisher Scientific, Waltham, MA, USA) [9].

For thrombin production, venous blood was drawn from healthy donors with $12 \mathrm{ml}$ syringes prefilled with 36 glass beads ( $\varnothing 4 \mathrm{~mm}$, borosilicate glass, Schäfer Glass $\mathrm{GmbH}$, Kaufbeuren, Germany). The filled syringes (10 $\mathrm{ml}$ of blood, 36 glass beads) were dynamically incubated for 20 minutes, resulting in thrombin and fibrin generation due to coagulation. Empty syringes of equal size were connected to the incubated syringes with a hose and inserted into the rotor. The connected syringe pairs were centrifuged at $930 \mathrm{~g}$ for 20 minutes, resulting in the separation of serum containing the thrombin from the cellular and fibrin clot components. The thrombin component was then automatically transferred into syringe $\mathrm{B}$. For fibrinogen production, venous blood was drawn from healthy donors with $12 \mathrm{ml}$ syringes prefilled with $1 \mathrm{ml}$ of citrate (4\% sodium citrate, Duomedica GmbH, Maintal, Germany). The filled syringes ( $11 \mathrm{ml}$ of blood, $1 \mathrm{ml}$ of citrate) were connected to syringes of equal size prefilled with $1.2 \mathrm{ml}$ of ethanol (absolute for analysis, Merck KGaA, Darmstadt, Germany) and set into the automated centrifugation system. In the first centrifugation step at $930 \mathrm{~g}$ for five minutes, platelet-rich plasma (PRP), or for 20 minutes, plateletpoor plasma (PPP), respectively, was generated in syringe A. Plasma was then transferred into syringe $B$ and mixed with the prefilled ethanol [9].

The following cooled centrifugation step at $1{ }^{\circ} \mathrm{C}$ and 1100-2100 g for 20-30 minutes resulted in fibrinogen precipitation. The supernatant was transferred back into syringe $A$ resulting in the fibrinogen component at an adjustable volume in syringe $B$. By removing all remaining plasma supernatant and utilizing a precision scale (CP423S, Sartorius AG, Göttingen Germany), the fibrinogen amount was assessed. A turbidimetric method as described was employed for the fibrinogen concentration measurement. [50] All produced fibrinogen was mixed with $2 \mathrm{ml}$ of fibrinogen reagent $(116 \mathrm{~g} / \mathrm{l}$ ammonium sulfate, $1.4 \mathrm{~g} / \mathrm{l}$ guanidine hydrochloride, $9 \mathrm{~g} / \mathrm{l}$ EDTA, deionized water, $\mathrm{pH}$ value of 4.9). Photometric measurements were performed after $120 \mathrm{sec}$ at $405 \mathrm{~nm}$ and compared to measurements with human plasma fibrinogen (341576100MG, Merck Millipore Corp., Billerica, MA, USA) of known concentration $(25 \mathrm{mg} / \mathrm{ml}$ ) (9). The sealant quality 
was determined by mixing the thrombin and fibrinogen components at equal volumes and evaluating the clotting properties via clot formation size of the formed clot and adhesive strength.

\section{Intervention}

All patients underwent modified radical mastectomy (MRM) and axillary dissection extended to level III. Although the same technique was followed in both groups, we minimized the use of electrocautery. We did sharp dissection and ligation of the visible lymph vessels and blood vessels. After MRM, the intervention group received AFG. The AFG (consisting of thrombin and fibrinogen) was sprayed after the area bed of surgery (chest and axillary region $4 \mathrm{ml}$ each) was completely clear from oozing. Gentle pressure was applied at least five minutes over the surgery area. In the control group, we performed MRM using the same technique without using AFG. We inserted two separated vacuum drains at the axilla and under the skin flap at both groups. We removed the drains after draining fluid volume less than $30 \mathrm{cc}$ per 24 hours $[9,10]$.

Then, we evaluated the volume of drained fluid in the postoperative period and length of hospital stay regarding the duration required to remove the drain. We also compared and noted the number of lymph nodes found on axillary dissection and the histopathology results.

\section{Statistical analysis}

We utilized SPSS 21 set edition to analyze the data.

\section{RESULTS}

The number of research subjects for each group amounted to 20 people, so the total number of subjects in this study was 40 . In this study, $10 \%$ of patients were excluded, four out of 44 patients due to flap necrosis and infection. Therefore, it has met the minimum required sample size. The characteristics of research subjects, in general, can be seen in Table 1 .

Based on Table 3, there was no statistical difference in histopathology type of breast cancer, number of excised axillary lymph nodes, and tumor size between the two groups. Furthermore, a significant reduction in seroma volume reduction could be seen, favoring the AFG group ( $p<0.001)$. In addition, the AFG group had a significantly shorter length of stay in the hospital compared to the control group $(p<0.001)$.
Table 1. Characteristics of patients in the treatment and control groups

\begin{tabular}{lll}
\hline & \multicolumn{2}{c}{ Group } \\
\cline { 2 - 3 } Variable & $\begin{array}{l}\text { Treatment } \\
\mathbf{N}=\mathbf{2 0}\end{array}$ & $\begin{array}{l}\text { Control } \\
\mathbf{N}=\mathbf{2 0}\end{array}$ \\
\hline $\begin{array}{l}\text { Age (years) } \\
\quad \text { Mean } \pm \text { SD }\end{array}$ & $49.00 \pm 12.12$ & $45.70 \pm 8.15$ \\
Range (min-max) & $26.00-84.00$ & $28.00-54.00$ \\
Weight (Kg) & & \\
$\quad$ Mean \pm SD & $55.80 \pm 8.99$ & $56.25 \pm 7.66$ \\
Range (min-max) & $44.00-75.00$ & $44.00-80.00$ \\
Height (m) & & \\
$\quad$ Mean \pm SD & $1.56 \pm 0.05$ & $1.55 \pm 0.05$ \\
$\quad$ Range (min-max) & $1.45-1.65$ & $1.45-1.65$ \\
Body Mass Index & & \\
$\quad$ Mean \pm SD & $22.73 \pm 3.07$ & $23.53 \pm 3.37$ \\
$\quad$ Range (min-max) & $18.70-29.30$ & $17.60-33.30$ \\
Chest Circumference (cm) & & \\
$\quad$ Mean \pm SD & $86.70 \pm 16.99$ & $83.35 \pm 13.24$ \\
$\quad$ Range (min-max) & $52.00-114.00$ & $55.00-110.00$ \\
\hline
\end{tabular}

We analyzed the profile of components in the blood which might have influenced the quality of adhesive AFG. The data were analyzed using an unpaired t-test and we didn't find statistical differences between the two groups (Table 2 ).

Table 2. Comparison of blood profile between two groups.

\begin{tabular}{|c|c|c|c|}
\hline \multirow[b]{2}{*}{ Variable } & \multicolumn{2}{|c|}{ Group } & \multirow[b]{2}{*}{$\mathbf{P}$} \\
\hline & $\begin{array}{l}\text { Treatment } \\
\mathrm{N}=\mathbf{2 0}\end{array}$ & $\begin{array}{l}\text { Control } \\
\mathrm{N}=20\end{array}$ & \\
\hline Hemoglobin $(\mathrm{g} / \mathrm{dL})$ & & & 0.625 \\
\hline Mean \pm SD & $11.39 \pm 1.58$ & $11.14 \pm 1.63$ & \\
\hline Range (min-max) & $8.80-13.90$ & $8.30-13.80$ & \\
\hline PT (seconds) & & & 0.060 \\
\hline Median & 11.35 & 12.35 & \\
\hline Range (min-max) & $9.80-13.30$ & $10.10-21.10$ & \\
\hline APTT (seconds) & & & 0.718 \\
\hline Mean \pm SD & $27.61 \pm 3.70$ & $28.09 \pm 4.60$ & \\
\hline Range (min-max) & $20.00-36.00$ & 20.10-41.70 & \\
\hline INR & & & 0.583 \\
\hline Mean \pm SD & 0.90 & 0.90 & \\
\hline Range (min-max) & $0.80-1.01$ & $0.83-1.12$ & \\
\hline Platelets (105/uL) & & & 0.165 \\
\hline Mean \pm SD & 263.50 & 238.50 & \\
\hline Range (min-max) & $158.00-429.00$ & $103.00-597.00$ & \\
\hline Fibrinogen (mg/dL) & & & 0.407 \\
\hline Mean \pm SD & $399.47 \pm 117.65$ & $375.71 \pm 47.19$ & \\
\hline Range (min-max) & 151.50-678.00 & 270.90-496.60 & \\
\hline Album (g/dL) & & & 0.832 \\
\hline Mean $\pm S D$ & $3.38 \pm 0.46$ & $3.35 \pm 0.39$ & \\
\hline Range (min-max) & $2.50-4.00$ & $2.66-4.29$ & \\
\hline
\end{tabular}

PT, prothrombin time; APTT, activated partial thromboplastin time; INR, international normalizing ratio.

For numerical data, the p-value is tested by using an unpaired t-test if the data is normally distributed, with the alternative Mann Whitney test if the data is not normally distributed. Significance value based on $\mathrm{p}$-value $<0.05 \mathrm{Sign}^{*}$ indicates $\mathrm{p}$-value $<0.05$ means significant or statistically significant. 
Table 3. Comparison of blood profile between two groups.

\begin{tabular}{|c|c|c|c|}
\hline \multirow[b]{2}{*}{ Variable } & \multicolumn{2}{|c|}{ Group } & \multirow[b]{2}{*}{$\mathbf{P}$} \\
\hline & $\begin{array}{l}\text { Treatment } \\
\mathbf{N}=\mathbf{2 0}\end{array}$ & $\begin{array}{l}\text { Control } \\
\mathrm{N}=20\end{array}$ & \\
\hline Histopathology & & & NS \\
\hline Invasive ductal carcinoma & 20 & 20 & \\
\hline Others & 0 & 0 & \\
\hline Stadium & & & NS \\
\hline Stage I & 20 & 20 & \\
\hline Stage II & 0 & 0 & \\
\hline Number of lymph node on ALND & & & 0.885 \\
\hline$<10$ & 7 & 7 & \\
\hline $10-30$ & 10 & 7 & \\
\hline$>30$ & 5 & 4 & \\
\hline Tumor Size & & & 0.954 \\
\hline$<2 \mathrm{~cm}$ & 5 & 4 & \\
\hline $2-5 \mathrm{~cm}$ & 10 & 9 & \\
\hline$>5 \mathrm{~cm}$ & 7 & 5 & \\
\hline Total volume of drainage $(\mathrm{cc})$, Mean \pm SD & $516 \pm 60.56$ & $1164 \pm 74.47$ & $<0.0001$ \\
\hline Length of stay (days), Mean \pm SD & $3.6 \pm 0.33$ & $4.55 \pm 0.26$ & $<0.0001$ \\
\hline
\end{tabular}

ALND, axillary lymph node dissection. For numerical data, the $p$-value is tested by using an unpaired t-test if the data is normally distributed, with the alternative Mann Whitney test if the data is not normally distributed. Significance value based on $p$-value $<0.05$ Sign $*$ indicates $p$-value $<0.05$ means significant or statistically significant.

\section{DISCUSSION}

The use of fibrin glue has been described in many situations, such as repair of the peripheral nerves and other visceral, fistula occlusion, cerebral tumor surgery, skin grafting, and application to burned patients. The continuing evolution in the preparation and use of fibrin glue is emphasized in the literature. Its general applicability is partly due to its unique wound healing characteristics of hemostasis, tissue adhesion, growth factors, and cytokines. Reports thus far have demonstrated decreased hematoma formation, seroma formation, postoperative swelling, and healing time [6-8].

On the other hand, there is an extremely high incidence of seroma formation after breast surgery, especially after mastectomy. In Indonesia, mastectomy is still the most common procedure to manage breast cancer. In terms of the seroma volume reduction methods, there have been numerous reports on the benefits of using fibrin glue. Fibrin glues interact with damaged tissue during surgical procedures, promoting fibroblast growth and wound healing. In addition, it helps hemostasis by preventing hematomas, which delay the surgical healing process, making the lymphatic branches impermeable and reducing seroma formation. Our study was conducted to determine the efficacy of AFG in reducing seroma production after mastectomy. Our study demonstrated a lower rate of seroma production in patients using AFG compared to conventional drain. However, the total seroma volumes were significantly higher in the conventional group rather than the AFG group. Although other studies reported a lack of benefit using AFG compared to traditional drain, our research, similar to Chan et al. [10], reported the benefit of fibrin glue in reducing seroma in patients undergoing quadrantectomy or mastectomy with axillary dissection. Tasinato et al. [11] also reported a reduction in seroma, duration, and the number of evacuative suctions in patients on whom fibrin glue spray was used compared with those whose axillary fossa was only washed with povidone-iodine or saline solution.

AFG has great benefits in breast cancer surgery for reducing seroma volume and shortening the length of hospital stay $(p<0.001)$. In addition, it is believed that fibrin sealant acts by improving hemostasis and tissue adherence.

Fibrin sealants reproduce the final stages of the enzymatic coagulation cascade, in which fibrinogen is converted to fibrin in the presence of thrombin, factor XIII, fibronectin, and ionic calcium. Fibrin glue also acts by inducing local hemostasis (modulation of the local inflammatory response) and/or adhering to apposed tissues (mechanical support). However, the use of commercial fibrinogen adhesives remains limited by the high cost. In this study, we demonstrated a method for obtaining fibrinogen from the blood for AFG production, and compared with commercial fibrin glue, 
AFG has the advantages of not causing tissue rejection reactions or stimulating fibroblast growth. Furthermore, the precipitation of plasma proteins concentrates not only fibrinogen but also other desirable and undesirable components, such as XIII and plasminogen. Plasmin, a derivative of plasminogen, is the major proteolytic enzyme that acts to dissolve the clot. Due to this tendency of plasmin to destroy the fibrin clot, an antifibrinolytic agent such as aminocaproic acid should be added to glue component II to retard clot lysis and stabilize the tissues to allow scar formation [11].

Another advantage of fibrin adhesive is its low predisposition to infection. For example, the growth of staphylococci in blood clots is ten times higher than in fibrin clots and 100 times higher than in fibrin clots containing factor XIII. However, disadvantages of patientderived fibrin glue preparations were found in low reproducibility due to variations between individuals [12].

\section{CONCLUSIONS}

The use of AFG showed a significant reduction in both seroma volume and incidence. Besides, it also had a significant decrease in the time and length of hospital stay until the drains were removed, and it led to a decrease in the bill compensating to the extent of its relatively high cost. However, further extensive prospective studies and more prominent retrospective meta-analysis studies are recommended to reach a final decision about this technique.

\section{DECLARATIONS}

\section{Ethics Approval}

The study was reviewed by the ethics committee of Hasan Sadikin General Hospital No. LB.02.01/X.6.5/3/2020

\section{Competing of Interest}

The authors declare no conflict of interest regarding the publication of this paper.

\section{Acknowledgment}

The authors thank all staff of the Department of Oncology, Head and Neck Surgery Hasan Sadikin General Hospital Bandung, Indonesia, for providing the data.

\section{REFERENCES}

1. Bray F, Ferlay J, Soerjomataram I, et al. Global cancer statistics 2018: GLOBOCAN estimates of incidence and mortality worldwide for 36 cancers in 185 countries. CA Cancer J Clin. 2018;68(6):394-424.

2. Azhar $Y$, Agustina $H$, Abdurahman $M$, Achmad D. Breast cancer in West Java: Where do we stand and go?. Indones J Cancer. 2020;14(3):91-6.

3. Akinci $M$, Cetin B, Aslan S, Kulacoglu H. Factors affecting seroma formation after mastectomy with full axillary dissection. Acta Chir Belg. 2009;109:481-483.

4. Junior NO. Hubungan antara seroma dengan body mass index dan kadar lekosit cairan seroma. Surgical Oncology Consultant [dissertation]. Bandung: Padjajaran University; 2010.

5. Pogson CJ, Adwani A, Ebbs SR. Seroma following breast cancer surgery. Eur J Surg Oncol. 2003;29:711-7.

6. Udén P, Aspegren K, Balldin G, et al. Fibrin adhesive in radical mastectomy. Eur J Surg. 1993;159(5):263-5.

7. Langer S, Guenther JM, DiFronzo LA. Does fibrin sealant reduce drain output and allow earlier removal of drainage catheters in women undergoing operation for breast cancer? Am Surg. 2003;69(1):77-81.

8. Carless PA, Henry DA. Systematic review and metaanalysis of the use of fibrin sealant to prevent seroma formation after breast cancer surgery. $\mathrm{Br} J$ Surg. 2006;93(7):810-9.

9. Düregger K, Frenzel S, Eblenkamp M. Autologous fibrin glue: automated production and adhesive quality. Curr Dir Biomed Eng. 2017;3:397-400.

10. Chang YT, Shih SL, Loh EW, Tam KW. Effects of fibrin sealant on seroma reduction for patients with breast cancer undergoing axillary dissection: metaanalysis of randomized controlled trials. Ann Surg Oncol. 2020;27(13):5286-95.

11. R. Tasinato, M. Godina, L. Griggio et al., "Prevenzione della linforrea ascellare nelle pazienti sottoposte a linfadenectomia per carcinoma mammario," Acta Chirurgica Italica,1993;49, pp. 479-484

12. Cavichiolo, Benthien J, Buschle M, \& Carvalho B. Comparison of fibrin adhesives prepared by 3 different methods. International Archives of Otorhinolaryngology, 2013; 17(1), 62-65. https:// doi.org/10.7162/S1809-97772013000100011 